\title{
Iron status in intrauterine contraceptive device users
}

\author{
*Wahda B. Al-Youzbaki; ** Luma S. AL-Nuri **Janan Gazzi \\ Department of Pharmacology, College of Medicine* \\ Department of Biochemistry College of Medicine ${ }^{* *}$, University of Mosul.
}

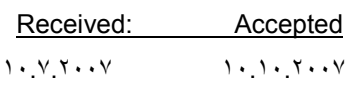

\begin{abstract}
The objective of this study is to evaluate the effect of one year use of Copper-Tr $\wedge \cdot A$ intrauterine contraceptive devices (IUCDs) on iron status of the body. It represent a Cohort study that was carried at Family Planning Center in AL-Batool Teaching Hospital, during the period from April $r \ldots r$ - August $r . . v$. Thirty women enrolled in this study, age ranged between $r .-\varepsilon r$ years, and with initial level of hemoglobin $(\mathrm{Hb}) \geq 1 \cdot \mathrm{g} / \mathrm{dl}$, were followed up at the time just before the insertion, then after 1 months and one year of the insertion of the IUCDs. Another thirty healthy women age ranged between $r \cdot-\varepsilon r$ years who did not use neither hormonal contraceptives nor IUCDs were considered as a control group, all followed by measuring $\mathrm{Hb}$ level and PCV by Cyanomethaemoglobin method, serum iron and total iron binding capacity (TIBC) using Enzymatic Calorimetric method and percent iron saturation was calculated by equation.

The results of this study showed that IUCDs caused a significant decrease in the mean serum level of $\mathrm{Hb}, \mathrm{PCV}$ and iron among the IUCDs users after 7 months and one year of the insertion of the IUCDs compared with the initial serum level at the time of the insertion. But a significant decrease in TIBC and \% saturation only after one year of the insertion of the IUCDs. Also there were a significant decrease in mean serum $\mathrm{Hb}$ and \% saturation of the IUCDs users after 7 months in comparison with the non users, while a significant decrease in all the iron status parameters of IUCDs users after one year in comparison with the non users. There were no significant difference between the iron status parameters of IUCDs users in relation with number of children the IUCDs users have delivered.

This study concluded that the Copper-TrA.A IUCDs use for one year cause a significant decrease in the iron status parameters, which is more with the increase duration of use but not affected by the number of children of the users of the IUCDs. It is recommended that iron supplementation, be a part of the IUCDs services provided in Family Planning Centers in the view of the high prevalence of anemia among women in child bearing age in Iraq.
\end{abstract}

Keywords: contraceptive, hemoglobin, ferritin.

$$
\begin{aligned}
& \text { الخلاصة } \\
& \text { تهنف هذه الدراسة إلى تقييم تأثير إستخدام لوالب منع الحمل ولمدة سنة على مستوى الحديد في الجسم. }
\end{aligned}
$$

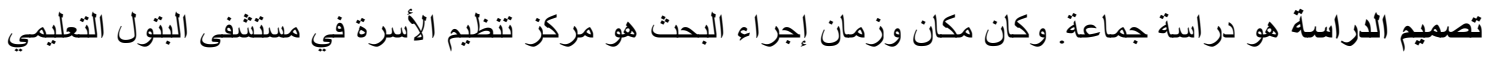

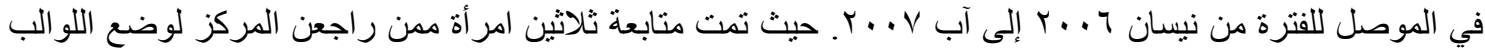

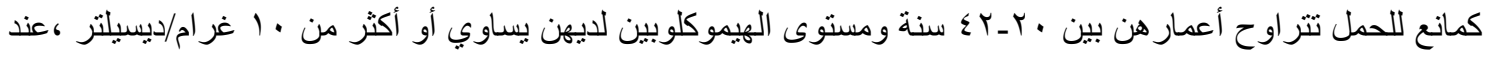

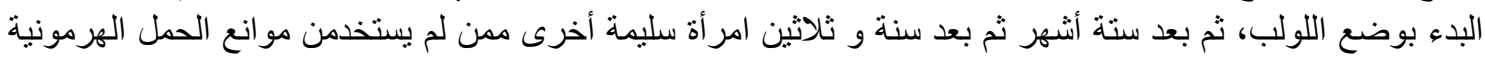

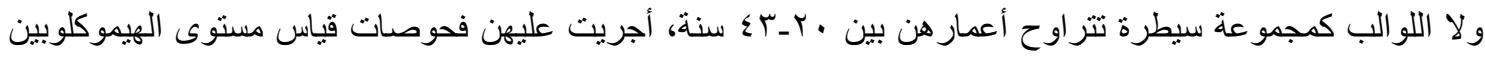

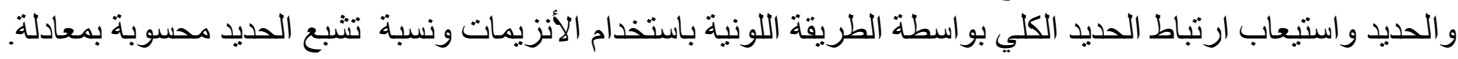

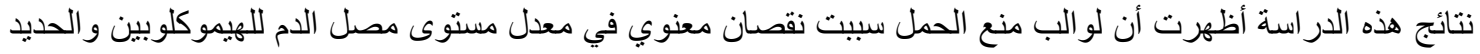

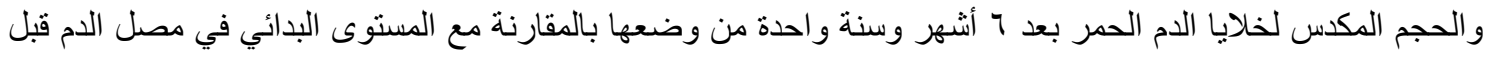

$$
\begin{aligned}
& \text { وضعها ولكن كان هنالك انخفاض كبير في مستوى استيعاب ارتباط الحديد الكلي ونسبة تشبع الحديد فقط بعد سنة واحدة الحنة } \\
& \text { r..A Mosul College of Pharmacy }
\end{aligned}
$$




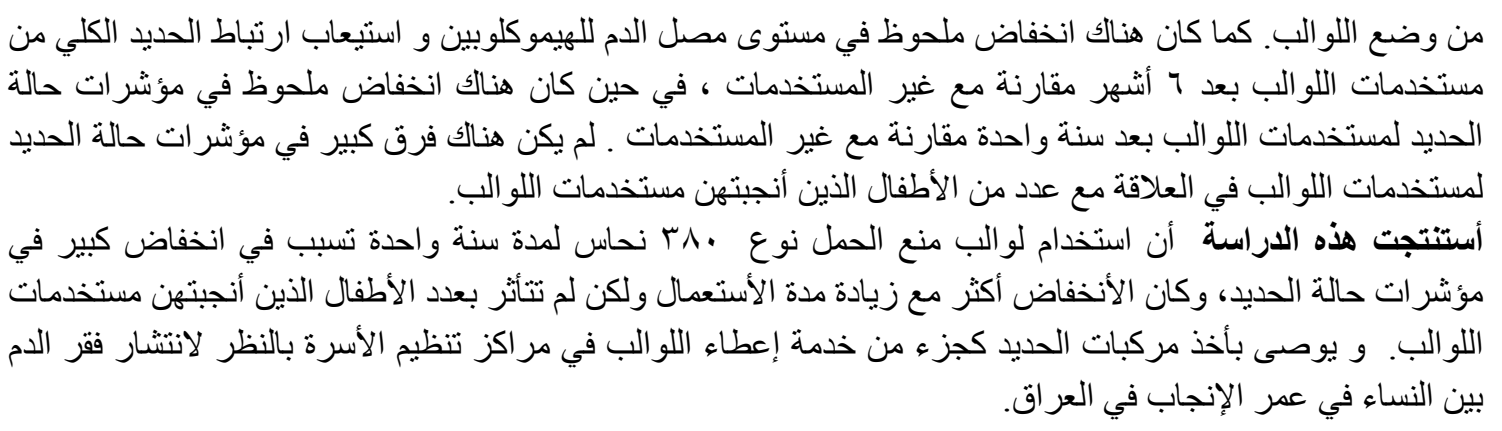

T he intrauterine contraceptive device is the most commonly used form of reversible contraception worldwide; approximately $1 \leqslant 0$ million married women currently use it.' A local study in Mosul city in Iraq, found that IUCDs form the second most common contraceptive method used ( $r$ Y.A\%) after the oral pills (\&r. $7 \%){ }^{r}$ The predominant type of product, the copper IUCDs (a plastic T-shaped device with copper affixed to it) was developed over $r$. years ago and has become the standard bearer for intrauterine contraception, due to its long-term effectiveness, safety and affordability. ${ }^{r,}$

For some women, however, copper IUCDs can cause increased menstrual blood loss and pain ${ }^{r, p, r, \gamma}$. These side effects often lead to early removal $, 9, \cdots$. It was reassuring to note that long term IUCDs use even beyond three years did not have any adverse effect on hemoglobin status. It is possible that women who had severe menorrhagea had the device removed earlier and such a removal parse served to protect women from the risk of developing anemia associated with IUCDs use. "As bleeding and pain are the most common reasons for removal rates of $1 . \%$ in the first year and up to $0 . \%$ within 0 years. ${ }^{\text {ir }}$

Anemia is one of the major public health problems among women belonging to the reproductive age group. Hemoglobin surveys indicate that a sizable proportion of women is anemic even in the non-pregnant state ${ }^{(1)}$. Population studies have shown that when menstrual loss increased, there was an increased risk of anemia even among nonanemic women in developed countries. 1 $\$ 10$

In countries where a relatively high prevalence of anemia exist, it is of vital importance to study the effect of various contraceptive methods on iron status of contraceptive initiators so that family planning services may address the problem of anemia as part of the contraceptive services provided to their clients.'

The aim of this study was to evaluate the effect of one year use of Copper-TrA.A IUCDs on the iron status of the body and the effect of the period of use and the number of children on it.

\section{Subjects and Methods}

This study was conducted from April $r \ldots r$ to August $r \ldots r$ in which women who were attending the Center of Family Planning at ALBatool Hospital in Mosul city for receiving contraception were participated in this study. These women currently married, not pregnant neither lactating nor infertile at the time of the study and $r$. of them age ranged between $r$.$\varepsilon r$ years with initial level of $\mathrm{Hb}$ equal or more than $1 \cdot \mathrm{gm} / \mathrm{dl}$, were arranged for insertion of IUCDs.

These women were followed by taking blood samples at the initial time of the insertion then after $r$ months and one year of the insertion of the IUCDs. Another r. healthy women not pregnant neither lactating nor infertile, age ranged between $r \cdot-\varepsilon r$ years with regular menstrual period who did not use neither hormonal contraceptives nor IUCDs were selected as control group. The $\mathrm{Hb}$ level in the blood was measured by cyanomethaemoglobin method, iron concentration and TIBC were measured in the serum by spectrophotometric method using (Randox kit, laboratories Ltd, UK). Percent iron saturation was calculated by the following equation ${ }^{(1 v)}$. 


\section{Serum Iron}

\section{Percent iron saturation $=$ $X, \ldots$ \\ TIBC}

Data were analyzed using t test to assess the significant differences between the mean values. Differences between observations were considered statistically significant at $\mathrm{P}$ value $<\cdot . \bullet$.

\section{Results}

There were significant decrease in $\mathrm{Hb}, \mathrm{PCV}$, iron serum level among the IUCDs users after 7 months and one year of the insertion of the IUCDs compared with the initial serum level at the time of the insertion. But significant decrease in TIBC and \% Saturation only after one year of the insertion of the IUCDs shown in table !.
Table $r$ : Shows that there were a significant decrease in the serum $\mathrm{Hb}$ and TIBC among IUCDs users after 7 months of IUCDs insertion in comparison to the non users (control).

Table $r$ shows that there were a significant decrease in the mean of serum $\mathrm{Hb}, \mathrm{PCV}, \mathrm{Fe}$, TIBC and percent

of iron saturation among IUCDs users after one year of IUCDs insertion in comparison to the non users (control) .

Table \&: Shows that there were a non significant difference between the iron status parameters of IUCDs users

after one year of use in relation with number of children they have delivered.

Table 1. Changes in iron status parameters among IUCDs Users

\begin{tabular}{|c|c|c|c|}
\hline & \multicolumn{3}{|c|}{ Mean \pm SD of IUCDs Users $(n=r \cdot)$} \\
\hline Parameters & At time of insertion & After 1 months & After one year \\
\hline $\mathrm{Hb}(\mathrm{g} / \mathrm{dl})$ & Ir.rV $\pm \cdot .90 \mathrm{a}$ & $11 . \vee \Upsilon \pm \cdot . \wedge r \mathrm{~b}$ & $11.11 \pm 1 . \cdot r c$ \\
\hline PCV \% & $r v . T r \pm r . T r a$ & $r 4 . r \pm r . r) b$ & r. $4 \pm r .17 \mathrm{c}$ \\
\hline $\mathrm{Fe}(\mu \mathrm{g} / \mathrm{dl})$ & $V \Lambda . r T \pm 1 \leqslant . r \mid a$ & $79 . \varepsilon r \pm 1 r .07 \mathrm{~b}$ & $7 r .0 \pm 11.0 \mathrm{C}$ \\
\hline $\operatorname{TIBC}(\mu \mathrm{g} / \mathrm{dl})$ & $r r r . \varepsilon \varepsilon \pm$ or. $r \leqslant a$ & $r r \cdot .0 \pm M r . r r a b$ & $r \cdot r \cdot \circ v \pm r q . \cdot r b$ \\
\hline$\%$ Saturation & $r r^{\prime} \cdot r \pm 0 . r r_{a}$ & $r \cdot .0 \cdot \pm \tau .\{\wedge a b$ & $r \wedge .9 \wedge \pm \varepsilon . \cdot 7 b$ \\
\hline
\end{tabular}

*(a,b,c) different letters (horizontally), means significant differen 
Irq J Pharm

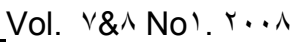

Table $r$. Comparison between iron status parameters among IUCDs users \& non users (Control) after 1 months.

\begin{tabular}{|c|c|c|c|}
\hline \multirow[b]{2}{*}{$\begin{array}{c}\text { Parameters } \\
\text { after ` months }\end{array}$} & \multicolumn{2}{|c|}{ Mean \pm SD } & \multirow[b]{2}{*}{ P-value } \\
\hline & $\begin{array}{l}\text { IUCDs users } \\
(n=r \cdot)\end{array}$ & $\begin{array}{l}\text { Control } \\
(n=r \cdot)\end{array}$ & \\
\hline $\mathrm{Hb}(\mathrm{g} / \mathrm{dl})$ & $11 . \vee 1 \pm \cdot . \wedge r$ & $1 Y . r 4 \pm 1.10$ & $<\cdot .0^{*}$ \\
\hline PCV \% & $r q . r \pm r . r 1$ & $r Y .1 r \pm r . Y \wedge$ & $>\cdot .0$ \\
\hline $\mathrm{Fe}(\mu \mathrm{g} / \mathrm{dl})$ & $79 . \varepsilon r \pm 1 Y .07$ & $V 4 . \varepsilon r \pm 10$ & $>\cdot .0$ \\
\hline $\mathrm{TIBC}(\mu \mathrm{g} / \mathrm{dl})$ & $r Y \cdot .0 \pm M Y . Y r$ & $r r q . r \pm r \varepsilon . v$ & $<\cdot .0^{*}$ \\
\hline \% Saturation & $r \cdot .0 \pm 7 . \varepsilon \Lambda$ & $r r \pm 0.1 r$ & $>. .0$ \\
\hline
\end{tabular}

* significant level.

Table r. Comparison between iron status parameters among IUCDs users \& non users (Control) after one year.

\begin{tabular}{|c|c|c|c|}
\hline \multirow[b]{2}{*}{$\begin{array}{c}\text { Parameters after } \\
\text { one year }\end{array}$} & \multicolumn{2}{|c|}{ Mean \pm SD } & \multirow[b]{2}{*}{ P-value } \\
\hline & $\begin{array}{l}\text { IUCDs users } \\
\qquad(n=r \cdot)\end{array}$ & $\begin{array}{l}\text { Control } \\
(n=r \cdot)\end{array}$ & \\
\hline $\mathrm{Hb}(\mathrm{g} / \mathrm{dl})$ & $11.1 \wedge \pm 1.0 r$ & Tr.rT $\pm 1.1 r$ & $<\because \cdot \cdot)^{* *}$ \\
\hline PCV \% & $r r .7 \pm r .17$ & $r \Upsilon . \Delta V \pm r .0 Y$ & $<\cdot \ldots 1^{* *}$ \\
\hline $\mathrm{Fe}(\mu \mathrm{g} / \mathrm{dl})$ & $74.0 \pm 11.0$ & $V \wedge . \wedge \pm 1 r . \wedge 0$ & $<\cdot \ldots 1^{* *}$ \\
\hline TIBC $(\mu \mathrm{g} / \mathrm{dl})$ & $r \cdot r .0 V \pm r q . \cdot r$ & $r r 4.0 \pm M 1 . \wedge 4$ & $<\cdot \ldots)^{* *}$ \\
\hline$\%$ Saturation & $r \wedge .9 \wedge \pm \varepsilon . \cdot 7$ & $r 1.7 V \pm 0.17$ & $<\cdot .0^{*}$ \\
\hline
\end{tabular}

Table «.s Relationship between iron status parameters among IUCDs users after one year and the number of children.

\begin{tabular}{|c|c|c|c|c|}
\hline \multirow[b]{2}{*}{ Parameters } & \multicolumn{3}{|c|}{ Mean \pm SD } & \multirow[t]{2}{*}{ p-values } \\
\hline & $1-r(n=1 \cdot)$ & $r-0(n=1 \cdot)$ & $>0(n=1 \cdot)$ & \\
\hline $\mathrm{Hb}(\mathrm{g} / \mathrm{dl})$ & $\mid 1 . r 1 \pm \cdot . \wedge$ & $11.11 \pm 1 . r 1$ & $11 . r+1 . \cdot \varepsilon$ & $>\cdot .0$ \\
\hline PCV \% & $r T . \checkmark \pm Y . Y V$ & $r r . \top \pm \varepsilon . \varepsilon$ & $r Y . T \pm Y . V 4$ & $>\cdot .0$ \\
\hline $\mathrm{Fe}(\mu \mathrm{g} / \mathrm{dl})$ & $71.9 \pm 1 . \leqslant 9$ & $75.7 \pm 10.9$ & $71 \pm 1 \cdot .94$ & $>\cdot .0$ \\
\hline TIBC $(\mu \mathrm{g} / \mathrm{dl})$ & $r \cdot q . Y \pm r Y . r)$ & $r \cdots . \wedge \pm r ฯ . r \wedge$ & $198.8 \pm 17 . r 9$ & $>\cdot .0$ \\
\hline$\%$ Saturation & $r q . r \pm r . \cdot 1$ & $r 9.9 \pm\{.70$ & $r Y . \wedge 0 \pm \varepsilon . \varepsilon r$ & $>\cdot .0$ \\
\hline
\end{tabular}




\section{Discussion}

In premenopausal women, serum ferritin levels were strongly dependent on the duration of menstrual bleeding, which in turn was related to the method of contraception. '^ Several investigators ${ }^{1}$-r. . have reported persistent excessive menstrual loss among IUCDs wearers. It has been suggested that continued excessive blood loss in long term IUCDs wearers were exacerbate the existing anemia among women in developing countries. "Even though data available from developed countries have not revealed any alteration in hematological profile in IUCDs wearers."

This study found a significant decrease in $\mathrm{Hb}$, PCV, iron serum level among the IUCDs users after 7 months and more after one year of the insertion of the IUCDs compared with the initial serum level at the time of the insertion. But significant decrease in TIBC and \% Saturation only after one year of the insertion of the IUCDs which indicates that this effects increase with the duration of use of IUCDs in the first year. These results are in agreement with a study done by Heikkinen et al., " who found that $v 1 \%$ of IUCDs users had reached iron deficient levels by the end of the follow up period ( 7 months).

Hassan et al. ${ }^{r r}$ found that the use of IUCDs for one year were significantly associated with the highest prevalence of anemia among all contraceptive users ( $7 \leqslant .9 \%$ ) and IUCDs users had lowest level of $\mathrm{Hb}$ compared to non users or users of other methods. In another study by Hassan et al., ${ }^{(1)}$ showed that the use of IUCDs produced a statistically significant drop in the $\mathrm{Hb}$ content and percent iron saturation levels after $1 r$ months of use, as compared to the use of combined oral contraceptive pills for the same period and the drop was greater with longer IUCDs use and recommended that iron supplementation be part of the IUCDs services provided in the family planning units.

In agreement with our study it found that menstrual was bleeding in women using hormonal contraception was significantly shorter than in those using IUCDs and ferritin levels were highest in present and former users of oral contraceptives, lower in those who currently used other methods, and lowest in current IUCDs users ${ }^{\wedge, \mathrm{rr}}$. It was concluded that iron stores can be quickly exhausted in a large majority of premenstrual women, which means that guidelines for dietary iron intake and supplementation (of a daily tablet containing I $\leqslant-r$. mg of ferrous iron), should take special needs of members of a population into consideration, such as women whose menstruation lasts 0 days or more, who have menstrual bleeding of strong intensity, who use an IUCD without gestagen, and who are blood donors.

Imperato et al.," ${ }^{19}$ found increasing uterine bleeding and a consequent significant drop in $\mathrm{Hb}$ level in women inserted with $\mathrm{Cu}$-IUCDs than those inserted with levonorgestrelreleasing IUCDs and suggested that the main reason of menorrhagea in women inserted with Cu-IUCDs probably is due to the shape of device and to copper surface area and concluded that levonorgestrel-releasing IUCDs is a new contraceptive method combining the advantages of both hormonal and intrauterine contraception. In addition, it can be considered as alternative method in the treatment of menorrhagea and dysfunctional uterine bleeding.

On the other hand, our results in our developing country are in contrast with the result obtained by other studies ${ }^{r s, r_{0}}$ who found no significant changes in $\mathrm{Hb}$ level or likelihood of anemia have been noted with copper IUCDs. Milsom et al. ${ }^{r \cdot}$ studied the influence of the Gyno-T rA.S IUCDs on menstrual blood loss and iron status and found that there were no significant changes recorded in iron status parameters during the ir months observation period following IUCDs insertion indicating that women from developed countries apparently tolerate an increase menstrual blood loss of about $00 \%$ without developing iron deficiency anemia. Iron stores were unchanged as in this study indicating an adequate increase in intestinal iron absorption. Accordingly, copper IUCDs can generally be used by women with anemia. ${ }^{r}$

This study demonstrated a significant decrease in mean serum $\mathrm{Hb}$ and \% saturation of the IUCDs users after 1 months in 
comparison with the non users, while a significant decrease in all iron status parameters of IUCDs users after one year in comparison with the non users. While in our previous case control study. ${ }^{r v}$ on the effect of the use of different contraceptives (hormonal and IUCDs) for the period $\cdot$ Y $_{-} 7$ years on iron status, found that IUCDs use caused only a significant decrease in PCV and statistical increase in percent of saturation of iron among IUCDs users than control. These results can be explained by a study performed by Prema (') who showed that there is no detorious effect on $\mathrm{Hb}$ status after long term use of IUCDs even beyond $r$ years and it is possible that these long term IUCDs users were those privileged individuals who had the least menstrual disturbance. It has also be shown that incidence of menorrhagea progressively decreases with increasing duration of use of IUCDs. ${ }^{\wedge}$

This study demonstrated a non significant difference between the iron status parameters of IUCDs users in relation with number of children they have delivered. In a study done on Danish women found that iron deficiency anemia was found in $r .7 \%$ of pre and $\cdot . r 4 \%$ of postmenopausal women and the pre menopausal multipara had lower serum ferritin than nulli and unipara. ${ }^{\text {rq }}$

This study concluded that the use The Copper-Tr^.A IUCDs for one year causes a significant decrease in the iron status parameters, which is more with the increase duration of use but not affected by the number of children of the users of the IUCDs. It is recommended that iron supplementation, be a part of the IUCDs services provided in Family Planning Centers in the view of the high prevalence of anemia among women in child bearing age in Iraq. Further studies are required to evaluate the relation between the parity and gravity of the IUCDs users and iron status of the body.

\section{References}

1. United Nations, Department of Economic and Social Affairs ( $r \ldots \varepsilon)$ World Contraceptive Use $r \ldots r$ available from URL

r... Mosul College of Pharmacy (http://www.un.org/esa/population/publication s/contraceptiver..r/WallChart CPr..r web. $\underline{\mathrm{xls}}$ ) (Accessed May $r \wedge$, r. . $\varepsilon$ ).

r. Al-Youzbaki WB. Contraceptive Practices in Mosul. Iraqi J Comm Med. Y. . $\leqslant ; । \vee(Y): \wedge 0_{-} 9$.

r. World Health Organization. Mechanism of action, safety and efficacy of intrauterine devices. Report of a WHO Scientific Group. World Health Organ Tech Rep Ser. 19^v; vor: 1-91.

๕. Trussell J, Leveque JA, Koenig JD, et al. The economic value of contraception: a comparison of 10 methods. Am J Public Health. 1990; $10: \leqslant 9 \leqslant-0 . r$.

•. Liedholm P, Rybo G, Sjoberg NO, Solvell L. Copper IUD - influence on menstrual blood loss and iron deficiency. Contracept. 19v०; IT:MVRTO.

ฯ. Andrade AT, Pizarro E, Shaw ST Jr, Souza JP, Belsey EM, Rowe PJ. Consequences of uterine blood loss caused by various intrauterine contraceptive devices in South American women. World Health Organization Special Programme of Research, Development and Research Training in Human Reproduction. Contracept. 191^;r৯: $1-11$.

v. Larsson G, Milsom I, Jonasson K, Lindstedt G, Rybo G. The long-term effects of copper surface area on menstrual blood loss and iron status in women fitted with an IUD. Contracept. 199r; $\leqslant \wedge: \leqslant \vee 1-\leqslant \wedge$.

$\wedge$. Sivin I and Stern J. Long-acting, more effective copper T IUDs: a summary of U.S.

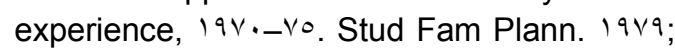
1. (1.): YTr-rAl.

१. Trieman K, Liskin L, Kols A, Rinehart W (1990) IUDs an update. Population Reports, Series B, No. 7. Johns Hopkins School of Public Health, Population Information Program, Baltimore, MD.

1.Cox $M$ and Blacksell SE. Clinical performance of the Nova-Tr^. IUD in routine use by the UK Family Planning and Reproductive Health Research Network: Irmonth report. Br J Fam Plann. r... r $; ; \mid \leqslant \Lambda_{-}$ 101.

11. Prema K. Hemoglobin levels in contraceptive

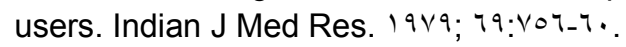

Ir.Human Reproduction Update. Intrauterine devices and intrauterine systems. The 
1r.ESHRE Capri Workshop Group. r...; $1 \leqslant(r): 19 V-r \cdot \Lambda$.

I . Sood SK. Iron deficiency anemia. Proc Nutr Soc India. 197v;r: $r$ 纟.

10. Halberg L, Hogdenhl A M, Nilson L, Rybo G. Menstrual blood loss- a population study variations at different ages and attempts to define normality. Acta Obstet Gynaecol Scand. 1974; \&0:Tr. - rr .

17. Jacobs A., Butler EG. Menstrual blood loss in iron deficiency anemia. Lancet. 1970;ii: $\varepsilon \cdot V_{-} \varepsilon \cdot q$.

IV. Hassan EO, El-Husseini M, El-Nahal N. The effect of 1 years use of the Cent $r \wedge$. A and oral Contraceptive pills on hemoglobin and Ferritin levels. Contracept. 1999; $\cdot(r): 11 \cdot 1-$ 1.0 .

1^.Burtis CA, Ashwood ER. Methods for determination of serum iron, iron binding capacity and transferrin saturation. In: Tietz, Textbook of Clinical chemistry. Fairbanks VF, Klieg G G (eds.) r rd edition. 1999:1 V.1. iv.r.

19. Milman N, Rosdahl N, Lyhne N, Jorgensen T, Graudal N. Iron status in Danish women aged ro-10 years. Relation to menstruation and method of contraception. Act Obstet Gynaecol Scand. 199r;Vr(^):7. 1-7.0.

$r \cdot$. Imperato F, Perniola G, Mossa B et al., [The role of copper-releasing intrauterine device or levonorgestrel-releasing intrauterine system on uterine bleeding and iron status (prospective study of $\wedge$ years)]. Minera

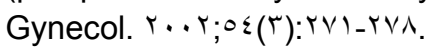

$r$. Milsom I, Andersson K, Jonasson $K$, Lindstedt $G$, Rybo $G$. The influence of the Gyne-T rA.S IUD on menstrual blood loss and iron status. Contracept. 1990; or (r): 1 V०iva.

rY. Heikkinen JE, Saure A, Ylostalo P. Serum ferritin levels in pills and IUD users. Contracep Deliv Syst. $\left.19 \lambda r ; \xi(r): \mid r V_{-}\right) \leqslant 1$.
rr.Hassan E O, El-Husseini M, El-Nahal N. The prevalence of anemia among clients of family planning clinics in Egypt. Contracept. $1999 ; 7 \cdot(r): 9 r-99$.

$r$ 纟. Milman N, Clausen j, Byg KE. Iron status in rฯA Danish women aged $\Lambda_{-} r$. years: Influence of menstruation, contraceptive method, and iron supplementation. Ann Hematol. 1991; $\vee V(1-r): 1 r-19$.

Yo. Andrade A, Pizarro Orchard E. Quantitative studies on menstrual blood loss in IUD

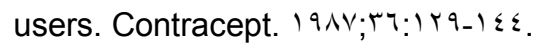

$r$ r. Task Force for Epidemiological Research on Reproductive Health. Effects of contraceptives on hemoglobin and ferritin. Geneva, Switzerland. Contracept. 199^;0^: (T)-TVT.

$r v$.World Health Organization. Medical eligibility criteria for contraceptive use. Geneva: WHO, r... .

r^.Al-Youzbaki WB, Mahmood IH, Al-Nuri LS. Iron status in hormonal contraceptives and IUCDs users. Iraqi J Comm Med. Y... ; IQ(s): rIr-riN.

rq.Datey S, Gaur LN, Saxena B N. Vaginal bleeding patterns of women using different contraceptive methods (implants, injectables, IUDS, oral pills). An Indian experience. An ICMR Task Force Study. Indian Council of Medical Research. Contraception. 1990;01(r)100-170.

$r \cdot$ Milman N, Kirchhoff M, Jorgensen T. Iron status markers, serum ferritin and hemoglobin in 1 rog Danish women in relation to menstruation, hormonal contraception, parity, and postmenopausal hormone treatment. Ann Hematol. 199r; ro(r): $971 . r$. 